\title{
Cementing Material on Mechanical Property of Calcareous Sand
}

\author{
X. B. Lu ${ }^{*}$, L. Wang and X. H. Zhang
}

Key Laboratory for Hydrodynamics and Ocean Engineering, Institute of Mechanics, Chinese of Academy, 100080, Beijing

\begin{abstract}
It is difficult to obtain high quality samples of natural material covering a range of densities and degree of cementation, so study on the sample preparation techniques with similar mechanical properties of natural samples are very important. Experiments were carried out to study the effects of cementation of different materials on the mechanical properties of calcareous sand, e.g., the effects of contents and types of cementation materials on the strength and the characteristics of stress-strain. It is shown that Portland cement is a good cementation agent, compared to calcite and gypsum. The strength of calcareous sand increases with the increase of Portland cement content.
\end{abstract}

Keywords: Calcareous sand, mechanical properties, cementation, Portland cement.

\section{INTRODUCTION}

Since the late 1970s there has been increasing interest in understanding the behavior of cemented calcareous sand which is widespread in ocean floor [1-9]. In the zone distributed calcareous sand, the design of piles is different with that in traditional soil zone [10-13]. The difficulties to understand the response of cemented sand is in obtaining high quality samples of natural material covering a range of densities and degree of cementation, and is also the high spetial variability in the degree of cementation, so that closely spaced samples may have significantly differing properties. These difficulties lead researchers to study the responses of artificially cemented soils [14-16]. Accordingly, various sample preparation techniques and cementing agents have been reported in the literature. The mechanical properties of the soils determines the engineering characteristics such as bearing capacity, stability etc. Thus it is practical to preparing samples with similar or close mechanical properties with the natural calcareous sand at the engineering site.

The first attempt to prepare artificially cemented soils was made by Akili \& Torrance [17] based on the deposition of calcite cement from calcite-enriched water by evaporation. However, the amount of calcite precipitated was negligible even over a long time. Later, a method to create calcite by chemical reaction was proved effective.

The main disfigurement of artificially cementing calcareous sand by using of early common methods is the addition of significant fractions of fines, with the cementing process nucleated from those fines. Recently, a cementing process, called CIPS (Calcite In Situ Precipitation System), has been developed [18-19]. CIPS needs a set of complex system, and the corresponding cementing process is long. Therefore, mixing-cementation-process is adopted in this paper. The

*Address correspondence to this author at the Key Laboratory for Hydrodynamics and Ocean Engineering, Institute of Mechanics, Chinese of Academy, 100080, Beijing; Tel: 861082544190; Fax: 861062561284;

Email: xblu@imech.ac.cn cement agent liquor is mixed with calcareous sand in a given proportion first, then the sand is made into samples and deposited for some days.

The aim of this paper is to study the effects of cementation on the mechanical characteristics of calcareous sand so as to provide some references for the sample preparing of calcareous sand.

\section{PHYSICAL PARAMETERS OF IN-SITU CALCARE- OUS SAND}

The calcareous sand used in the following experiments is obtained from the South China Sea near the Yongfu reef. The diameters of calcareous sand are generally larger than $0.1 \mathrm{~mm}$, thus the method of griddle analysis is adopted in grain series tests and the results are shown in Fig. (1). The main characteristic parameters are shown in Table $\mathbf{1}$.

The diameters of calcareous sand used in experiments are all less than $5.0 \mathrm{~mm}$, thus the pyknometer method is adopted to measure the specific gravity. Pure water and kerosene are used as the liquid media, respectively. The experiments are repeated twice. The specific gravity is 2.75 when using pure water as liquid media while it is 2.73 when using kerosene as liquid media. On the surface of sand grain, there exist salts which are easy to dissolve into water, which leads to the increase of specific gravity. Therefore, we adopt the value 2.73 measured using kerosene as liquid media. The relative densities are shown in Table 2.

\section{RESULTS OF TRIAXIAL EXPERIMENTS OF IN- SITU CALCAREOUS SAND}

Three types of samples are used to carry out the consolidated and drained (CD) shear experiments. The parameters of the three samples are shown in Table 3.

Shown in Fig. (2) are the CD curves under different confined pressures which there are obvious dilatancy under low confined pressure, for example, $50 \mathrm{kPa}$, taking sample B as example. With the increase of confined pressure, the failure strain increases and the volume becomes shrinkage from dilatancy. Fig. (2b) shows the curves of volume strain 


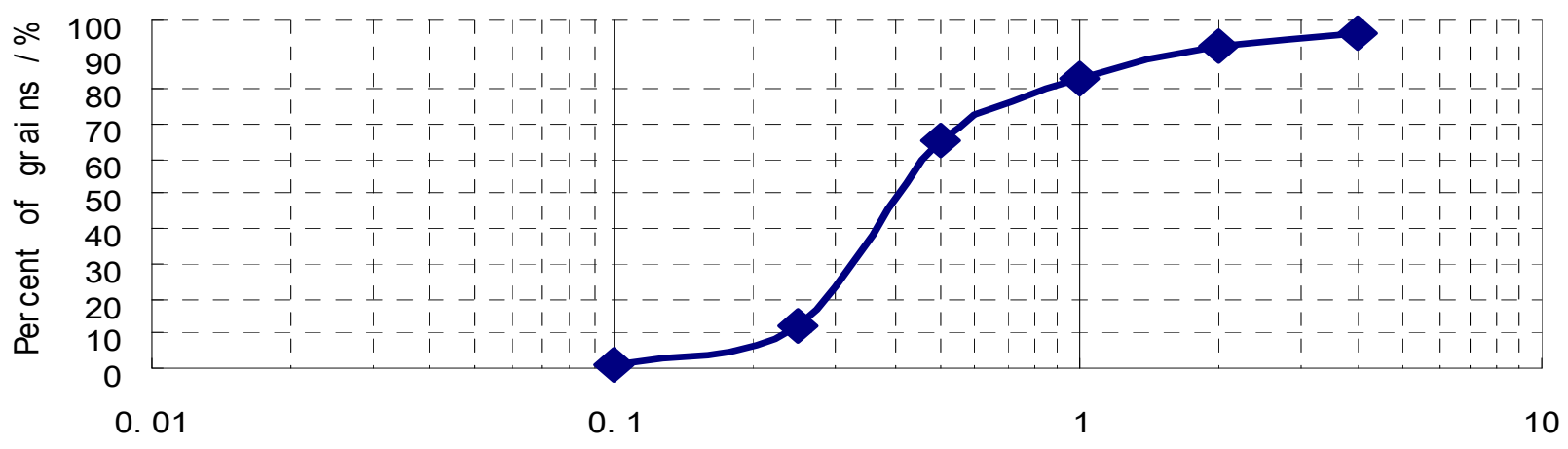

G ai n di amet er / mm

Fig. (1). Grain series of the calcareous sand used in experiments.

Table 1. The Grain Size Characteristics

\begin{tabular}{|c|c|c|c|c|c|}
\hline $\mathbf{d}_{60} / \mathbf{m m}$ & $\mathbf{d}_{\mathbf{5 0}} / \mathbf{m m}$ & $\mathbf{d}_{\mathbf{3 0}} / \mathbf{m m}$ & $\mathbf{d}_{\mathbf{1 0}} / \mathbf{m m}$ & $\mathbf{C}_{\mathbf{u}}$ & $\mathbf{C}_{\mathbf{c}}$ \\
\hline \hline 0.46 & 0.41 & 0.33 & 0.24 & 2.83 & 0.819 \\
\hline
\end{tabular}

(in which $\mathrm{d}_{60}, \mathrm{~d}_{50}, \mathrm{~d}_{30}, \mathrm{~d}_{10}$ are the maximum diameters corresponding to the $60 \%, 50 \%, 30 \%$ and $10 \%$ of the total quality, $\mathrm{C}_{\mathrm{c}}$ is the non-uniform coefficient, $\mathrm{C}_{\mathrm{c}}$ is the curvature coefficient)

Table 2. Specific Density and Porosity Ratio

\begin{tabular}{|c|c|c|c|}
\hline$\rho_{\min } / \mathbf{g} / \mathbf{c m}^{3}$ & $\rho_{\max } / \mathbf{g} / \mathbf{c m}^{\mathbf{3}}$ & $\boldsymbol{e}_{\max }$ & $\boldsymbol{e}_{\min }$ \\
\hline \hline 1.131 & 1.421 & 1.4138 & 0.9204 \\
\hline
\end{tabular}

Table 3. Basic Physical Index of Samples

\begin{tabular}{|c|c|c|c|c|c|c|c|c|}
\hline & $\rho_{\min } / \mathrm{g} / \mathbf{c m}^{3}$ & $\rho_{\max } / \mathbf{g} / \mathbf{c m}^{3}$ & $\rho_{\mathrm{d}} / \mathbf{g} / \mathbf{c m}^{3}$ & $d_{60}(\mathrm{~mm})$ & $d_{50}(\mathrm{~mm})$ & $d_{30}(\mathrm{~mm})$ & $d_{10}(\mathrm{~mm})$ & $\mathbf{D}_{r}$ \\
\hline A & \multirow{3}{*}{1.131} & \multirow{3}{*}{1.421} & 1.34 & \multirow{3}{*}{0.46} & \multirow{3}{*}{0.41} & \multirow{3}{*}{0.33} & \multirow{3}{*}{0.24} & 0.77 \\
\hline B & & & 1.26 & & & & & 0.51 \\
\hline $\mathrm{C}$ & & & 1.18 & & & & & 0.20 \\
\hline
\end{tabular}

(in which $D_{r}=\frac{e_{\max }-e}{e_{\max }-e_{\min }}, e_{\max }, e_{\min }, e$ are maximum pore ratio, minimum pore ratio and pore ratio of samples, respectively.)

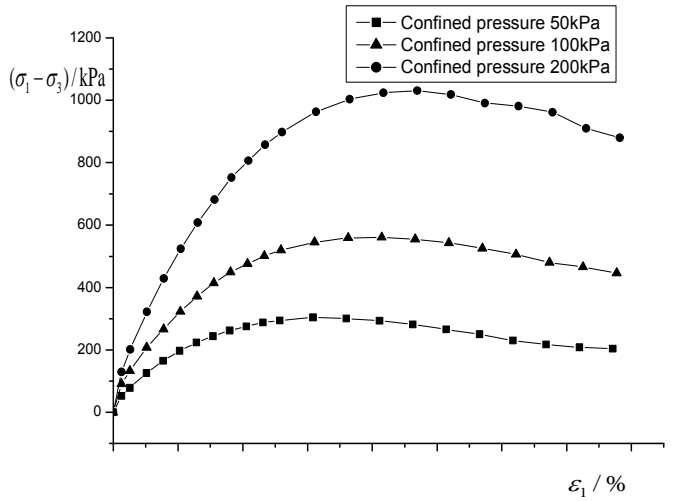

(a) Deviatoric stress axial strain curves

under different confined pressures

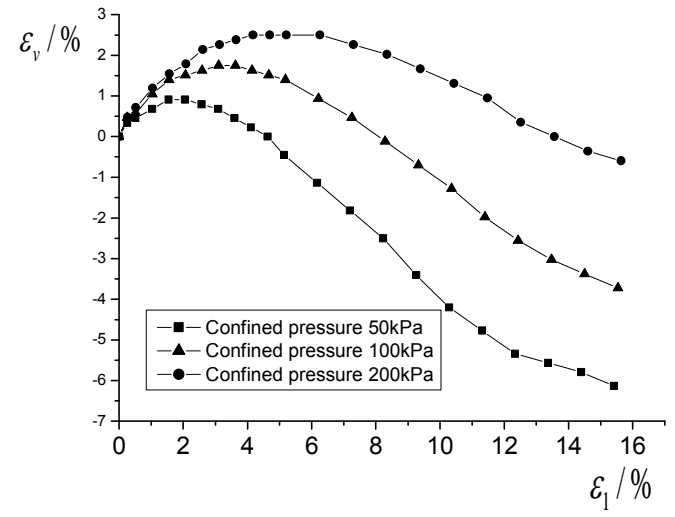

(b) volume strain axial strain curves

under different confined pressures

Fig. (2). The CD experimental curves of sample B. 
Table 4. The Strength Indexes of Samples Under Different Densities

\begin{tabular}{|c|c|c|c|}
\hline$\rho_{\mathrm{d}} / \mathbf{g} / \mathbf{~ c m}^{\mathbf{3}}$ & $\mathbf{1 . 3 4}$ & $\mathbf{1 . 2 6}$ & $\mathbf{1 . 1 8}$ \\
\hline \hline $\mathrm{C}(\mathrm{KPa})$ & 0 & 0 & 0 \\
\hline$\varphi\left({ }^{\circ}\right)$ & 48.2 & 47.7 & 46.4 \\
\hline
\end{tabular}

axial strain under the confined pressure of $200 \mathrm{kPa}$. It can be seen that the volume is almost shrinkage under the confined pressure of $200 \mathrm{kPa}$. The reason is that the calcareous sand is easy to be break up. With the increase of confined pressure, the peak stress and strain increase, for example, the peak stress is $1000 \mathrm{kPa}$ and the corresponding axial strain is $9 \%$ and the volume strain is $2.5 \%$ (dilatant) when the confined pressure is $200 \mathrm{kPa}$, while the peak stress is $250 \mathrm{kPa}$ and the corresponding axial strain is $6 \%$ and the volume strain is $1 \%$ (shrinkage) when the confined pressure is $50 \mathrm{kPa}$. The cohesions $\mathrm{C}$ and internal friction angles under different densities are shown in Table 4.

\section{RESULTS OF TRIAXIAL EXPERIMENTS OF ARTI- FICIAL CALCAREOUS SAND}

\section{Preparation of Artificial Samples}

In this paper, gypsum, calcite and Portland cement are used as the cementation media, respectively. Plaster powder is $400 \mathrm{mesh}$ size. The calcite powder is $400 \mathrm{mesh}$ size. The grade of the portland cement is P32.5.

Generally, calcareous sand may be cemented using the methods of ejection, mixture and electro-thermal. Although sintered method are used first, the cementation caused by this method is small, thus no samples made by this method is used in experiments. During preparing samples for the following experiments, the cementation media, calcareous sand and water are mixed according to a designed proportion first. The mixture is then put into modulus with a designed density. The samples are laid for three days for complete cementation before starting experiments.

\section{Results with Calcite as Cementation Media}

Fig. (3) shows the changes of stress-strain when the samples cemented by $5 \%$ mass of calcite. These experiments are carried out under the confined pressures of $50 \mathrm{kPa}, 100 \mathrm{kPa}$ and $200 \mathrm{kPa}$, respectively. The peak stress increases about $15 \%$ with cementation but the residual stresses are almost the same as that without cementation. The reason is that the increase of strength is caused by the cementation. The cementation by calcite is not very strong. Once the cementation is damaged, the cementation disappears totally. Thus the residual strength is the same for either the sample with and without cementation. The internal friction angle and the cohesion are 48.5 degree and 0 , respectively. The internal friction angle increases only a few relative to the samples containing no calcite. If we want to prepare samples with weak cementation and low increase of strength, calcite is a kind of appropriate cementation media.

\section{Results with Portland Cement as Cementation Media}

Experiments with Portland cement as cementation media are carried out under confined pressures of $50 \mathrm{kPa}, 100 \mathrm{kPa}$ and $200 \mathrm{kPa}$, respectively. Fig. (4) shows the curves of stress
- strain. The brittleness of the samples increases with the mass increase of Portland cement, especially under low confined pressure. With the increase of confined pressure, the failure strain increases. For example, the peak stress reaches when the strain is less than $1 \%$ when the content of Portland cement is $15 \%$ and the confined pressure is $50 \mathrm{kPa}$, while the peak stress reaches when the strain is $5 \%$ under the confined pressure of $200 \mathrm{kPa}$.

The increase of Portland cement mass has small effects on internal friction angle, but has large effects on cohesion. The cohesions are $0,10 \mathrm{kPa}, 50 \mathrm{kPa}, 100 \mathrm{kPa}$ and the internal friction angles are $46.4^{\circ}, 46.4^{\circ}, 45.0^{\circ}$ and $45.0^{\circ}$, respectively, when the Portland cement masses are $0 \%, 5 \%, 10 \%$ and $15 \%$, respectively. That means, Portland cement bonds the sand grains strongly except for its strong cohesion, so the cohesion increases greatly. If we want to prepare samples with largely increasing cohesion but few changes of internal friction, Portland cement is an idea cementation media. However, when the Portland cement mass is less than $5 \%$, the cementation effect is small.

\section{CONCLUSIONS}

The main conclusions are as follows:

1. The internal friction angle of calcareous sand used here is as large as 48 degree. There occurs dilatancy at low confined pressure, especially with large density, but when the confined pressure increases to only $200 \mathrm{kPa}$, the dilatancy disappears.

2. Different cementation material (calcite, Portland cement and gypsum) are used to investigate the effects of cementation media and the effects of cementation on the strength and stress-strain relation. According to experimental results Portland cement has obvious cementation effects. The strength of calcareous sand increases with the increase of Portland cement content.

3. The strength of the sample containing $15 \%$ Portland cement is $170 \%$ of that without Portland cement. The cohesions are $10 \mathrm{kPa}, 50 \mathrm{kPa}$ and $100 \mathrm{kPa}$ but the internal friction angle changes little when Portland cement contents are $5 \%$, $10 \%$ and $15 \%$, respectively. When using the calcite or gypsum as the cementation material, the cementation effects is little in the saturation condition.

4. Portland cement is a perfect cementation material for calcareous sand during preparing samples with strong cohesion. If samples with only a little increase of strength are required, calcite is suit. Different contents are required to prepare samples with different cementation degree.

\section{CONFLICT OF INTEREST}

The authors confirm that this article content has no conflicts of interest. 


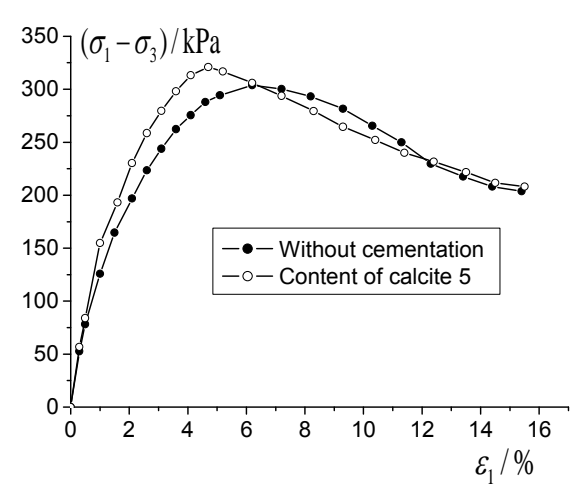

(a) Deviatoric stress axial strain curves under the confined pressure of $50 \mathrm{kPa}$

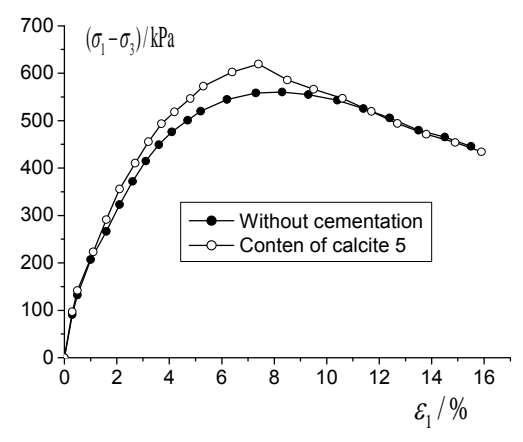

(c) Deviatoric stress axial strain curves under the confined pressure of $100 \mathrm{kPa}$

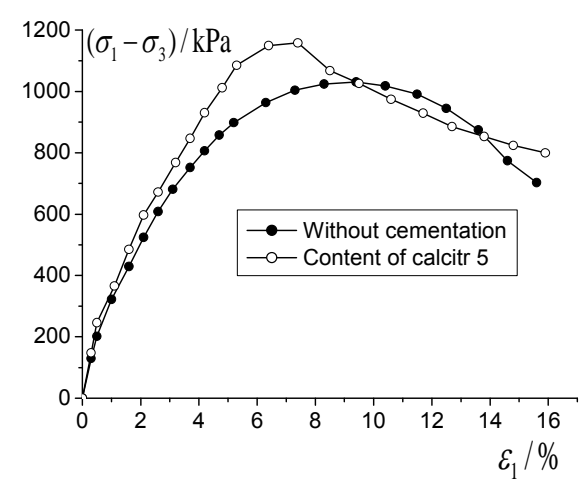

(e) Deviatoric stress axial strain curves under the confined pressure of $200 \mathrm{kPa}$

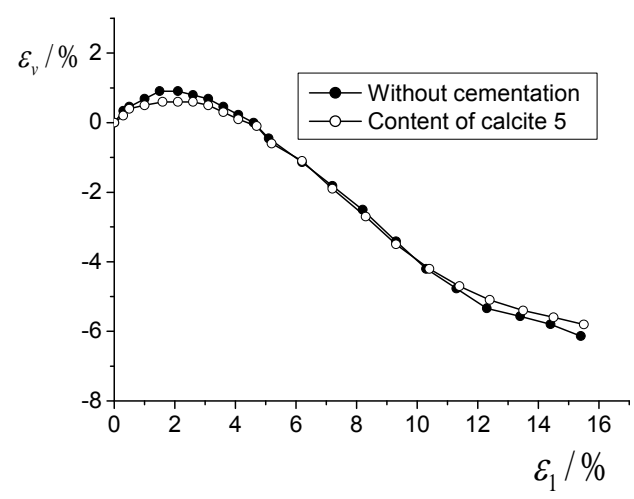

(b) Volume strain axial strain curves

under the confined pressure of $50 \mathrm{kPa}$

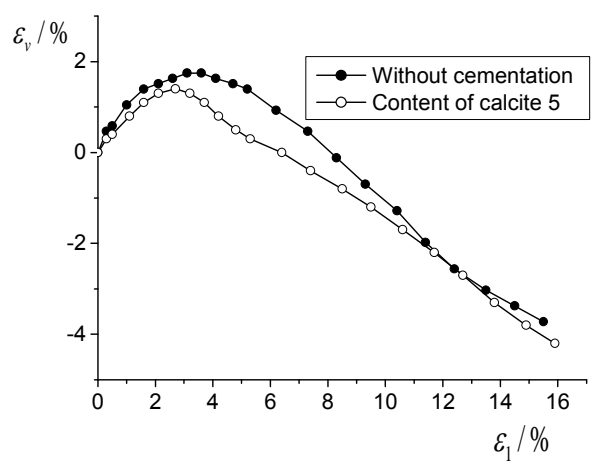

(d) volume strain axial strain curves

under the confined pressure of $100 \mathrm{kPa}$

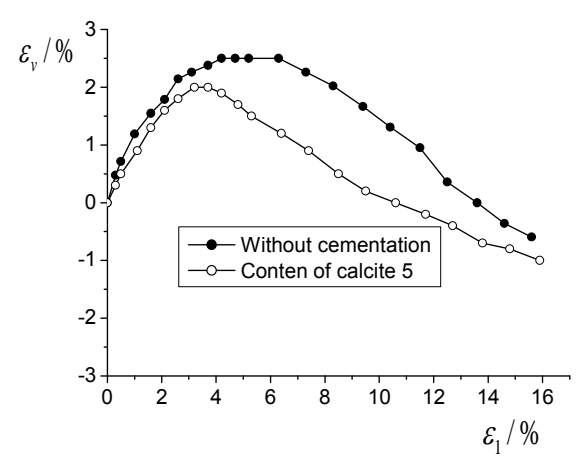

(f) volume strain axial strain curves

under the confined pressure of $200 \mathrm{kPa}$

Fig. (3). Experimental curves under CD conditions for the samples cemented by calcite. 


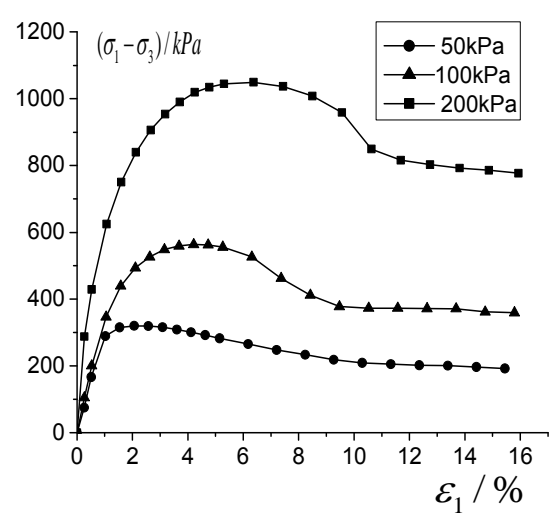

(a) Curves of deviatoric stress axial strain under different confined pressure

(Portland cement mass 5\%)

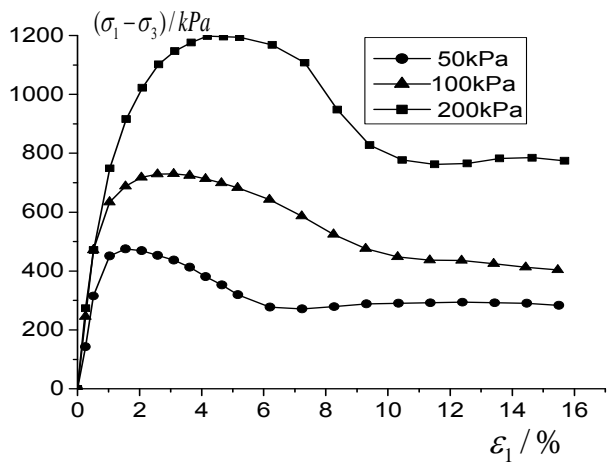

(b) Curves of deviatoric stress axial strain under different confined pressure

(Portland cement mass 10\%)

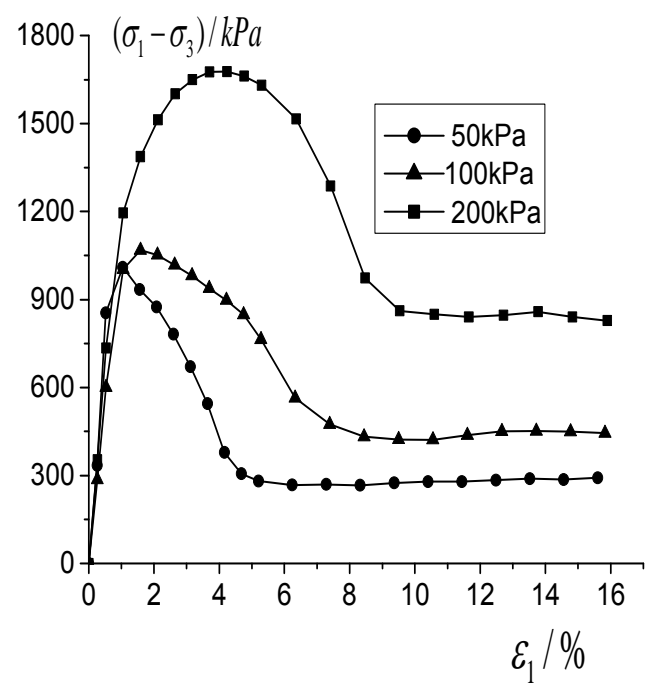

(c) Curves of deviatoric stress axial strain

under different confined pressure

(Portland cement mass 15\%)

Fig. (4). Experimental results under CD conditions for the samples contained cement.

\section{ACKNOWLEDGEMENT}

It is supported by National High Technology Research and Development Program of China (863) and National Natural Science Fund (No. 10772182).

\section{REFERENCES}

S. K. Saxena, and R. M.Lastrico, "Static properties of lightedly cemented sand", J. Geotech. Eng. Div., ASCE, vol. 104, no.12, pp.1449-1465, December 1978.

[2] Liu Chongquan and Wang Ren, "Initial study on the physical and mechanical properties of calcareous sand", Chinese soil Mech., vol. 19, no. 1, pp. 33-37, January 1998,
[3] J. R. C. De Mello and C. D. S. Amaral, "Closed-ended piles: testing and piling in calcareous sand", In: Proc. of 21th Annual offshore Technology Conference, Australia, Houston, 1989, pp. 341352.

[4] M.J. Cassidy, B.W. Byrne, G.T. Houlsby, "Modeling the behaviour of circular footings under combined loading on loose carbonate sand", Geotech., vol. 52, no. 10, pp.705-712, December 2002.

[5] M.J. Cassidy, D.W. Airey, J.P. Carter, "Numerical modeling of circular footings subjected to monotonic inclined loading on uncemented and cemented calcareous sands", J. Geotech, Geoenviron. Eng., $A S C E$, vol. 131, no. 1, pp. 52-63, January 2005,

[6] S. S. Sharma and M. Fahey, "Degradation of stiffness of cemented calcareous soil in cyclic triaxial tests", J. Geotech. Eng. Div., $A S C E$, vol. 129, no. 7, pp. 619-629, July 2003. 
[7] R.Desrosiers, A. J. Silva. "Strength behavior of marine sands at elevated confining stresses", Mar Georesour Geotech., vol. 20, no. 1, pp. 1-19, January 2002.

[8] L. Wang, X. B. Lu, Z. M. Shi. "Response of the bucket foundation in calcareous sand under horizontal dynamic load", Open Ocean Eng. J., vol. 3, pp. 20-30, 2010.

[9] X. B. Lu, L. Wang, Z. M. Shi. "Experimental study on the responses of bucket foundations in calcareous sand under vertical dynamic loading." Open Ocean Eng. J., vol. 3, pp. 50-55, 2010.

[10] J. F. Nauroy and Le P. Tirant., "Model tests of piles in calcareous sands", In: Proc. Conf. on geotech. practice in offshore Eng. Australia, Texas, 1983, pp. 356-369.

[11] J. T. Huang, and D. W. Airey, "Properties artificially cemented carbonate sand." J. Geotech. Geoenviron., vol. 124, no. 6, pp. 492499, June 1998.

[12] Lu Xiaobing, Wu Yongren, Jiao Bintian, S. Y. Wang, "Centrifugal experimental study of suction bucket under dynamic loading", ACTA Mech. Sinica., vol. 23, pp. 689-698, September, 20007.

[13] Wang Yihua, Lu Xiaobing S. Y. Wang, Z. M. Shi, "The responses of the bucket foundation under horizontal dynamic loading". Ocean Eng., vol. 33, pp. 964-973, May 2006.
[14] J. M. Dupas, and A. Pecker, "Static and dynamic properties of sand-cement", J. Geotech. Eng. Div., ASCE, vol. 105, no. 3, pp. 419-437, March 1979.

[15] T. Cuccovillo and M. R. Coop. "Yielding and pre-failure deformation of structured sand", Geotechnique., vol. 47, no. 3, pp. 491-508, August 1997.

[16] M. J. Lee, S. K. Choi, W. Lee, "Shear strength of artificially cemented sands", Mar Georesour Geotech., vol. 27, no. 3, pp. 201216, 2009.

[17] W. Akili and J. K. Torrance, "The development and geotechnical problems of Sabkha, with preliminary experiments on static penetration resistance of cemented sands", Q. J. Eng. Geol., vol. 14, pp. $59-73,1981$.

[18] M. A. Ismail, H. A. Joer, M. F. Randolph,. "Sample preparation technique for artificially cemented soils." Geotech. Testing J., vol. 23, no. 2, pp. 171-177, June 2000.

[19] M. A. Ismail, H. A. Joer, M. F. Randolph, Merrit A., "Cementation of porous materials using calcite", Geotechnique., vol. 52, no. 5, pp. 313-324, June 2002.

Received: July 26, 2012

Revised: August 12, 2012

Accepted: August 13, 2012

(C) Lu et al.; Licensee Bentham Open.

This is an open access article licensed under the terms of the Creative Commons Attribution Non-Commercial License (http://creativecommons.org/licenses/by$\mathrm{nc} / 3.0 /$ ) which permits unrestricted, non-commercial use, distribution and reproduction in any medium, provided the work is properly cited. 